\title{
RACKING SYSTEM DENGAN KEBIJAKAN CLASS BASED STORAGE DI GUDANG TIMUR PT INDUSTRI KERETA API (INKA) PERSERO
}

\author{
Ifa Saidatuningtyas, S.Si., MT. ${ }^{1)}$, Windy Nadilla Primadhani ${ }^{2}$ ) \\ ${ }^{1}$ D3 Logistik Bisnis, Politeknik Pos Indonesia \\ email: ifa.saida@poltekpos.ac.id \\ ${ }^{2}$ D3Logistik Bisnis, Politeknik Pos Indonesia \\ email: nadillawhindy@gmail.com
}

\begin{abstract}
Abstrak
Gudang PT INKA Persero mempunyai peranan penting bagi kelangsungan produksi Kereta Api Indonesia. Pada gudang diperlukan tata letak yang efektif dan efisien untuk mempermudah pencarian barang yang akan diproduksi. PT INKA Persero mempunyai tata letak gudang bahan baku yang belum efektif dan efisien, kurangnya pemenuhan kapasitas gudang secara optimal membuat re-layout gudang akan sangat diperlukan bagi perusahaan. Dengan menggunakan Racking System dalam pemaksimalan kapasitas gudang dan dengan kebijakan Class Based Storage diharapkan untuk menentukan penempatan barang yang tetap berdasarkan tingkat akitivitas penerimaan dan pengeluaran setiap barang yang ada. Sehingga diharapkan dapat meningkatkan kapasitas gudang secara lebih optimal dan penyimpanan bahan baku akan lebih tersusun rapi, sehingga dapat meminimalisir terjadinya overload pada gudang penyimpanan bahan baku. Hasil penelitian untuk re-layout gudang timur PT INKA Persero dengan Metode Racking System dan kebijakan Class Based Storage yaitu dengan hasil throughput untuk seluruh material adalah 31,665 yang mana control cable memiliki tingkat throughput tertinggi sebesar 7,990 throughput. Selanjutnya untuk hasil utilitas gudang setelah dilakukannya re-layout mengalami peningkatan utilitas sebesar $4.20 \%$.
\end{abstract}

\section{Kata Kunci: Class based storage, kapasitas Gudang, tata letak, relayout Gudang, PT INKA}

\section{PENDAhULUAN}

Gudang merupakan tempat untuk menyimpan barang baik barang mentah (raw materials) yang akan diproses pada tahap selanjutnya ataupun bahan jadi (finished goods) yang akan dikirimkan ke konsumen [1]. Gudang sendiri merupakan kunci penting dari kesuksesan supply chain pada era modern [2]. Gudang juga merupakan salah satu pendukung dan bagian terpenting dalam sistem produksi pada perusahaan [3].

Gudang adalah bagian penting dalam perusahaan manufaktur. PT INKA Persero merupakan Badan Usaha Milik Negara (BUMN) yang bergerak pada manufaktur kereta api. Oleh karena itu, gudang memegang peranan sangat penting pada PT INKA Persero. PT INKA memproduksi barang dengan sistem make-to-order (MTO) dalam produksi kereta api. PT INKA membutuhkan gudang yang efektif dan efisien dalam penanganan dan penyimpanan bahan baku.
Penempatan dan penyimpanan material di Gudang memegang peranan penting dalam memperlancar kegiatan produksi. Penempatan material yang jauh dari pintu masuk/keluar barang menyebabkan diperlukannya waktu yang lebih banyak dan jarak yang lebih jauh untuk penyimpanan dan penempatan barang tersebut. Untuk mengefektifkan dan mengefisiensikan operasional Gudang diperlukan pengaturan tata letak suatu Gudang.

Tata letak penempatan barang yang baik adalah tata letak yang memungkinkan barang yang tersimpan dapat terjangkau dan jarak pemindahan yang minimum. Kondisi tata letak dan pengaturan pada Gudang yang baik merupakan yang dapat menghindari kerugian dan meminimalkan biaya dan mempercepat produksi dan pelayanan pada Gudang [3]. Berikut adalah beberapa kebijakan pengaturan dan tata letak suatu Gudang [4]:

a. Kebijakan randomized, dimana setiap item yang datang akan diletakkan secara acak pada lokasi 
penyimpanan manapun dalam gudang, asalkan tempat / ruang penyimpanan tersebut masih cukup;

b. Kebijakan dedicated storage, dimana prinsipnya adalah material dengan kecepatan pergerakan material yang tinggi ditempatkan dekat dengan pintu Input / Output (I/O);

c. Kebijakan penyimpanan tetap (Dedicated Storage Policy); Item disimpan pada lokasi tertentu tergantung tipe itemnya;

d. Kebijakan penyimpanan bersama (Shared Storage Policy); Kebijakan yang berada pada titik ekstrem random dan dedicated storage policy.

Metode Class based storage digunakan untuk menyimpan material menurut popularitas, yaitu material yang bersifat fast moving disimpan didekat pintu masuk dan keluar barang agar meminimalisir jarak material handling yang akan menyimpan dan mengambil material pada warehouse. Pengaturan tata letak Gudang dengan menggunakan kebijakan Class based storage dapat mengetahui jarak tempuh material handling dalam melakukan penyimpanan dan pengeluaran barang sehingga barang yang bersifat fast moving dapat diletakkan didekat pintu masuk dan keluar gudang.

Penelitian dengan objek kajian Gudang PT INKA Persero telah banyak dilakukan sebelumnya. Topik penelitian pada objek kajian PT INKA antaralain rancang bangun aplikasi Gudang [5], perancangan ulang tata letak menggunakan metode ALDEP [6], perancangan tata letak dengan metode Systematic Layout Planning (SLP) [7]. Penelitian mengenai tata letak Gudang dengan menggunakan metode class-based storage telah dilakukan oleh Gozali (2020)[1]. Akan tetapi penulis belum menemukan penelitian mengenai tata letak Gudang yang menggunakan objek kajian PT INKA dan metode class-based storage.

\section{METODE PENELITIAN}

Permasalahan yang diangkat pada penelitian ini adalah perencanaan tata letak Gudang pada PT INKA dengan menggunakan metode class-based storage. Pada proses pengerjaan penelitian ini, penulis tidak melakukan perhitungan biaya secara keseluruhan, perkiraan biaya hanya berkisar pada pengadaan rak. Biaya pembuatan rak ini didapatkan melalui internet yang akan dijadikan bahan acuan dalam perhitungan pengadaan rak dalam re-layout gudang. Analisis tata letak ini hanya dilakukan pada Gudang timur PT INKA Persero.

Area Gudang timur PT INKA memiliki volume Gudang sebagai berikut:

$\begin{array}{lll}\text { Panjang } & : & 24 \mathrm{~m} \\ \text { Lebar } & : & 15 \mathrm{~m} \\ \text { Tinggi } & : & 12 \mathrm{~m} \\ \text { Luas } & : & 360 \mathrm{~m}^{2} \\ \text { Volume } & : & 4320 \text { meter }^{3}\end{array}$

Dengan ukuran luas masing-masing blok penyimpanan pada gudang Timur PT INKA Persero:

Tabel 1. Ukuran luas penyimpanan Gudang Timur PT

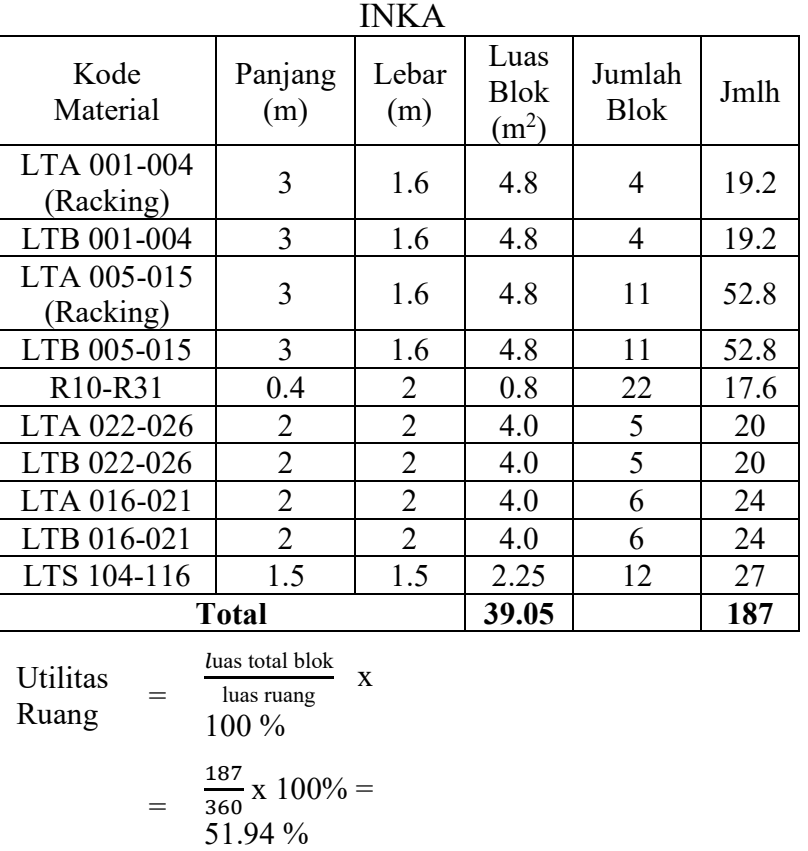

Adapun tahapan dan urutan proses metode class based storage yang dilakukan sebagai berikut:

1. Menentukan Dimensi Material

Material yang disimpan dalam gudang PT INKA Persero sangat beragam dimensi yang berjumlah 408 material.

2. Perhitungan Space Requirement (Kebutuhan Ruang) Perhitungan Space Requirement ini digunakan untuk mencari tahu kapasitas kebutuhan ruang masingmasing material yang akan disimpan pada gudang PT INKA Persero.

Space Requirement $=$ Luas packaging $x$ kebutuhan luas permukaan...........(1)

3. Perhitungan Throughput dan Perhitungan Jarak Perpindahan Material

Hal ini dilakukan untuk mengetahui berapa jarak dari blok penyimpanan dengan pintu keluar masuknya material pada gudang (In/Out).

Jumlah material masuk + Jumlah material keluar

$d i j=|x i-x j|+|y i-y j|$

4. Perhitungan Material Handling

Pengukuran material handling forklift sebagai alat material handling menempuh lintasan yang sama pada repetisi peletakan dan pengambilan bahan baku

5. Perhitungan Luas Aisle

Perhitungan luas Aisle digunakan agar forklift yang digunakan di Gudang Timur PT INKA Persero dapat lebih efektif dan efisien dalam menyimpan dan mengeluarkan material di gudang.

6. Pengurutan Throughput dan Pembentukan Kelas 
Pengurutan throughput dan pembentukan kelas ini dilakukan untuk menentukan material yang termasuk fast moving dan slow moving serta menentukan kelaskelas dari material untuk memudahkan karyawan dalam mengambil material yang disimpan pada Gudang

7. Menentukan Dimensi Rak Penyimpanan Dimensi rak penyimpanan memiliki fungsi agar material yang disimpan dengan packaging berbeda beda dapat tersimpan sesuai dengan ukuran dimiliki.

6. Jumlah Rak

Dalam menentukan jumlah rak yang akan digunakan terkait dengan hasil re-layout gudang

8. Menentukan Biaya untuk Pengadaan Rak dan Pallet Perhitungan biaya pengadaan rak yaitu kebutuhan pallet yang digunakan dalam penyimpanan barang yang dikalikan dengan level rak yang akan digunakan serta akan dikalikan dengan harga rak yang sesuai dengan tipe barang yang akan disimpan.

\section{HASIL DAN PEMBAHASAN}

a. Perhitungan Space Requirement (Kebutuhan Tempat Penyimpanan)

Perhitungan kebutuhan tempat penyimpanan dilakukan dengan persamaan (1). Adapun rumus Kebutuhan Tempat Penyimpanan yaiu mencari jumlah kebutuhan tempat penyimpanan yang dihitung dengan cara mengonversikan jumlah bahan baku ke satuan kardus yang merupakan packaging dalam penyimpanan material pada Gudang dan dikalikan dengan kebutuhan luas permukaan material.

Berikut merupakan contoh perhitungan Space Requirement

Connector Winsta Locking Lever pada gudang timur PT INKA Persero

Space Requirement : $(12 \times 7 \mathrm{~cm}) \times 10$

Space Requirement : $840 \mathrm{~cm}^{2}=0.084 \mathrm{~m}^{2}$

b. Perhitungan Jarak Perpindahan Material Layout dan frekuensi perpindahan (Throughput)

Throughput dihitung menggunakan persamaan (2), dengan perhitungan sebagai berikut:

Jumlah Material Masuk : 62 kardus

Jumlah Material Keluar : 124 kardus

$(\mathrm{T}): 62+124=\mathbf{1 8 6}$ frekuensi perpindahan

Perhitungan jarak perpindahan menggunakan metode penghitungan jarak recticlinear berdasarkan frekuensi keluar masuk material pada gudang. Pengukuran jarak ini menggunakan asumsi bahwasanya forklift sebagai alat material handling menempuh lintasan yang sama dalam pengambilan bahan baku. Perhitungan recticlinear menggunakan persamaan (3).

c. Perhitungan Material Handling

Material Handling Forklift yang dipakai adalah yang berukuran 3 ton dan 5 ton dengan merek CAT.

\section{d. Penentuan Luas Aisle (Gang-Gang) pada Gudang} Timur

Dimensi terpanjang forklift 5 Ton dapat dihitung sebagai berikut:

$d=\sqrt{p^{2}+1^{2}}$

$d=\sqrt{3^{2}+1.99^{2}}$

$d=\sqrt{9+3.96}=3.6 \mathrm{~m} \approx 4$ meter

Selanjutnya dilakukan penghitungan Allowance untuk forklift 5 Ton, yaitu:

Allowance $=\frac{15}{100} \times 3.6=0.54 \mathrm{~m}$

Total lebar aisle adalah jumlah dari dimensi terpanjang forklift 5 Ton dengan allowance yang telah ditetapkan yaitu:

Lebar aisle $=3.6+0.54=4.14 \mathrm{~m}$

dan dibulatkan menjadi $4 \mathrm{~m}$.

e. Pengurutan Throughput dan Pembentukan Kelas

Pembentukan kelas menggunakan dua prinsip yaitu similarity dan popularity. Kedua prinsip tersebut untuk mengefektifkan material handling dalam sistem pengelompokkan material yang. Pembentukan kelas terbagi menjadi 3, kelas A Fast Moving (80\% 10\% item), Kelas B Medium Moving (13\% 15\%item), dan Kelas C Slow Moving (7\% 75\% item). Berikut merupakan pengelompokkan material:

Tabel 2 Pembentukan Kelas

\begin{tabular}{|c|c|c|c|}
\hline Prioritas & Prinsip & Penggolongan & Kategori \\
\hline \multirow{5}{*}{1} & \multirow{5}{*}{ Similarity } & \multirow{5}{*}{ Jenis Material } & $\begin{array}{l}\text { Material } \\
\text { Part \& } \\
\text { fastening }\end{array}$ \\
\hline & & & $\begin{array}{l}\text { Komp. } \\
\text { Interior \& } \\
\text { Piping }\end{array}$ \\
\hline & & & $\begin{array}{l}\text { Komp. } \\
\text { Bogie \& } \\
\text { Propulsi }\end{array}$ \\
\hline & & & $\begin{array}{l}\text { Komp. } \\
\text { Bogie \& } \\
\text { Equipment }\end{array}$ \\
\hline & & & $\begin{array}{l}\text { Cat \& } \\
\text { Rubber }\end{array}$ \\
\hline 2 & Popularity & Throughput & $\begin{array}{l}\text { Peringkat } \\
1-408\end{array}$ \\
\hline
\end{tabular}




\section{f. Menentukan Rak Penyimpanan}

Dimensi pallet yang digunakan berukuran $120 \times 100$ x $14 \mathrm{~cm}^{3}$. Perusahaan membutuhkan beberapa pallet untuk proses pengangkatan bahan baku oleh forklift.

Dimensi pallet yang akan digunakan ini akan

\begin{tabular}{|c|c|}
\hline Utilitas Gudang Sebelum Re-layout & : $\quad 51.94 \%$ \\
\hline Utilitas Gudang Sesudah Re-layout & : $\quad 54.1 \%$ \\
\hline Peningkatan & $: \quad 4.2 \%$ \\
\hline
\end{tabular}

menentukan lebar rak pada re-layout gudang usulan di PT INKA Persero. Berikut merupakan kapasitas pallet serta dimensi rak penyimpanan masing-masing material setelah dilakukan re-layout gudang:

Tabel 3 Dimensi Rak Penyimpanan Sesudah Re-Layout

\begin{tabular}{|c|c|c|c|c|c|}
\hline Blok & $\begin{array}{c}\mathrm{P} \\
(\mathrm{cm})\end{array}$ & $\begin{array}{c}\mathrm{L} \\
(\mathrm{cm})\end{array}$ & $\begin{array}{c}\mathrm{T} \\
(\mathrm{cm})\end{array}$ & Pallet & $\begin{array}{c}\text { Luas } \\
\left(\mathrm{m}^{2}\right)\end{array}$ \\
\hline LTA 001 & 925 & 300 & 175 & 21 & 27.75 \\
\hline LTA 002 & 551 & 400 & 175 & 16 & 22.04 \\
\hline LTA 003 & 700 & 300 & 175 & 15 & 21 \\
\hline LTA 004 & 551 & 400 & 175 & 16 & 22.04 \\
\hline LTA 005 & 721 & 300 & 175 & 18 & 21.63 \\
\hline
\end{tabular}

Tabel 4 Biaya Pengadaan Rak Penyimpanan

\begin{tabular}{|l|l|l|l|l|l|l|l|}
\hline \multicolumn{1}{|c|}{ Bagian rak } & Kebutuhan/rak & $\begin{array}{c}\text { Pjg } \\
(\mathrm{m})\end{array}$ & $\begin{array}{c}\text { Pjg } \\
\text { Total } \\
(\mathrm{m})\end{array}$ & Bahan & Harga/ Meter & $\begin{array}{c}\text { Harga Total } \\
\text { 1 Rak }\end{array}$ & $\begin{array}{c}\text { Harga total 10 } \\
\text { rak }\end{array}$ \\
\hline Upright beams & 4 & 1.5 & 6 & Baja & $242,000 / \mathrm{m}$ & $1,452,000$ & $14,520,000$ \\
\hline Load beams & 2 & 8 & 16 & Baja & $242,000 / \mathrm{m}$ & $3,872,000$ & $38,720,000$ \\
\hline Siku Penopang & 4 & 0.31 & 1.24 & Baja & $60,000 / \mathrm{pcs}$ & 240,000 & $2,400,000$ \\
\hline Baut & 32 & & & Baut baja & $450,00 / \mathrm{pcs}$ & 14,400 & 144,000 \\
\hline Total & & & & & $9,461,200$ & $55,784,000$ \\
\hline
\end{tabular}

\section{h. Perancangan Layout Gudang Timur Usulan}

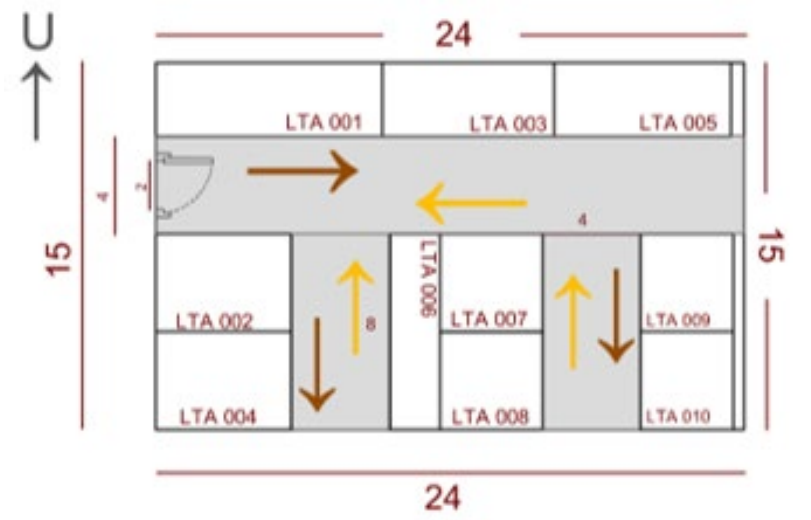

Gambar 1 Layout Gudang Timur Usulan

Penjelasan mengenai re-layout gudang timur PT INKA Persero dengan skala 1:100:

\begin{tabular}{|l|c|l|l|l|l|}
\hline \multicolumn{1}{|c|}{ Blok } & $\begin{array}{c}\text { P } \\
(\mathrm{cm})\end{array}$ & $\begin{array}{c}\mathrm{L} \\
(\mathrm{cm})\end{array}$ & $\begin{array}{c}\text { T } \\
(\mathrm{cm})\end{array}$ & Pallet & $\begin{array}{c}\text { Luas } \\
\left(\mathrm{m}^{2}\right)\end{array}$ \\
\hline LTA 006 & 206.2 & 800 & 175 & 8 & 16.5 \\
\hline LTA 007 & 419.5 & 400 & 175 & 12 & 16.8 \\
\hline LTA 008 & 419.5 & 400 & 175 & 12 & 16.8 \\
\hline LTA 009 & 378 & 400 & 175 & 12 & 15.12 \\
\hline LTA 010 & 378 & 400 & 175 & 12 & 15.12 \\
\hline Total & & & & $\mathbf{1 4 2}$ & $\mathbf{1 9 4 . 8}$ \\
\hline
\end{tabular}
Utilitas Ruang
$\begin{aligned} & \text { luas total blok } \\
& \text { luas ruang }\end{aligned}$
$=$

\section{g. Biaya Pengadaan Rak dan Pallet}

Rak penyimpanan membuutuhkan upright beams, dan load beams, dan siku penopang sebanyak 4, 2, dan 4 buah, dengan kebutuhan baut sebanyak 32 buah baut baja. Perhitungan biaya pengadaan rak penyimpanan dapat dilihat pada Tabel 4. Sedangkan biaya pengadaan pallet dengan bahan yang digunakan adalah kayu pinus dengan Panjang 120 m, lebar 100 $\mathrm{m}$, dan tinggi $14 \mathrm{~m}$, adalah sebanyak 142 pallet. 
melakukan pengolahan data, didapatkan rancangan penempatan produk untuk setiap jenis produk menurut tingkat pergerakannya. Pada gambar re-layout denah gudang diatas dapat diketahui, serta memiliki lebar aisle dengan allowance yaitu 4 meter untuk mempermudah material handling dalam melakukan penyimpanan dan pengeluaran material di gudang timur PT INKA Persero. Layout usulan tersebut memiliki luas penyimpanan blok sebesar $194.8 \mathrm{~m}^{2}$ dengan luas gudang timus keseluruhan adalah $360 \mathrm{~m}^{2}$. Untuk utilitas ruang pada re-layout usulan yaitu: Utilitas Ruang: $\frac{\text { luas total blok }}{\text { luas ruang }} \times 100 \%=\frac{194.8}{360} \times 100 \%=$ $54.1 \%$.

4) Re-layout gudang material yang akan diusulkan kepada PT INKA Persero bedasarkan permasalahan yang terjadi pada gudang tersebut yang selanjutnya dipecahkan dengan menggunakan metode class based storage. Berikut merupakan kapasitas dari masingmasing blok penyimpanan:

Tabel 5 Kapasitas Blok Penyimpanan sesudah Re-Layout Gudang

\begin{tabular}{|c|c|c|l|l|}
\hline BP & $\begin{array}{c}\text { LBP } \\
\left(\mathrm{cm}^{2}\right)\end{array}$ & $\begin{array}{c}\text { JLPM } \\
\left(\mathrm{cm}^{2}\right)\end{array}$ & $\begin{array}{c}\text { Space } \\
\text { kosong }\end{array}$ & \multicolumn{1}{|c|}{ Kapasitas } \\
\hline LTA 001 & 277500 & 277500 & - & $\begin{array}{l}\text { Sesuai dengan } \\
\text { kapasitas } \\
\text { material }\end{array}$ \\
\hline LTA 002 & 220400 & 220400 & - & $\begin{array}{l}\text { Sesuai dengan } \\
\text { kapasitas } \\
\text { material }\end{array}$ \\
\hline LTA 003 & 210000 & 210000 & - & $\begin{array}{l}\text { Sesuai dengan } \\
\text { kapasitas } \\
\text { material }\end{array}$ \\
\hline LTA 004 & 220400 & 210052 & 10348 & $\begin{array}{l}\text { Terdapat space } \\
\text { kosong }\end{array}$ \\
\hline LTA 005 & 216300 & 216280 & $20 \mathrm{~cm}^{2}$ & $\begin{array}{l}\text { Terdapat space } \\
\text { kosong }\end{array}$ \\
\hline LTA 006 & 164960 & 164932 & $28 \mathrm{~cm}^{2}$ & $\begin{array}{l}\text { Terdapat space } \\
\text { kosong }\end{array}$ \\
\hline LTA 007 & 167800 & 144189 & 23611 & $\begin{array}{l}\text { Terdapat space } \\
\text { kosong }\end{array}$ \\
\hline LTA 008 & 167800 & 167725 & $75 \mathrm{~cm}^{2}$ & $\begin{array}{l}\text { Terdapat space } \\
\text { kosong }\end{array}$ \\
\hline LTA 009 & 151200 & 151114 & $86 \mathrm{~cm}^{2}$ & $\begin{array}{l}\text { Terdapat space } \\
\text { kosong }\end{array}$ \\
\hline LTA 010 & 151200 & 118026 & 33174 & $\begin{array}{l}\text { Terdapat space } \\
\text { kosong }\end{array}$ \\
\hline
\end{tabular}

5) Pusat dan jarak blok penyimpanan dengan pintu keluarmasuknya material pada Gudang Timur PT INKA Persero dirancang berdasarkan throughput tertinggi hingga troughput terendah. Throughput tertinggi akan disimpan didekat pintu keluar masuknya material pada gudang dan throughput terendah akan disimpan menjauhi pintu keluar masuknya material pada gudang.

\section{KESIMPULAN}

Berdasarkan hasil analisis dan untuk menjawab perumusan masalah yang ada, didapatkan hasil sebagai berikut:

1. Pada penelitian ini, perencanaan racking system dalam penataan tata letak baru di gudang timur PT INKA Persero mampu menyimpan 408 material tanpa adanya overload pada blok penyimpanan, perencanaan racking system pada gudang timur PT INKA Persero telah di rancang satu level rak penyimpanan dengan 9 blok penyimpanan yang memiliki tinggi $150 \mathrm{~cm}$ dengan lebar dan panjang rak ditentukan dari jumlah total luas penyimpanan material yang menempati rak tersebut.

2. Perencanaan racking system pada gudang timur PT INKA Persero, dapat meminimalisir space kosong dan overload pada gudang, serta dapat meningkatkan utilitas gudang dengan mengoptimalkan luas gudang yang telah ada sebesar $4.2 \%$ dari utilitas gudang sebelumnya yaitu $51.94 \%$.

3. Perbaikan tata letak gudang timur PT INKA Persero yaitu dengan cara pengelompokan class, yang terbagi dalam 3 kelompok class yaitu class A, B, dan C. Pengelompokan class dilakukan berdasarkan material yang termasuk kedalam fast moving disimpan pada class A didekat pintu keluar masuknya material dengan jarak perpindahan antara blok penyimpanan dan pintu keluar masuknya barang yaitu 6.1 meter, material yang termasuk medium moving disimpan pada class B dengan jarak perpindahan antara blok penyimpanan dan pintu keluar masuknya barang yaitu 21.5 meter dan material yang termasuk slow moving disimpan pada class $\mathrm{C}$ menjauhi pintu keluar masuknya material dengan jarak perpindahan antara blok penyimpanan dan pintu keluar masuknya barang yaitu 26.67 meter. Dengan dilakukannya re-layout gudang timur PT INKA Persero yang berdasarkan nilai throughput material, dapat meminimalisir jarak yang ditempuh material handling dalam melakukan penyimpanan dan pengeluaran barang dari gudang.

4. Biaya yang diperlukan dalam pengadaan 10 Rak Gudang usulan PT INKA Persero yaitu Rp. $\mathbf{5 5 , 7 8 4 , 0 0 0}$. Rak yang digunakan dengan bahan baku baja dengan 4 bahan baku yaitu Upright beams berjumlah 4 buah yang memiliki panjang satuan $1.5 \mathrm{~m}$ per rak dengan harga per meter $242,000 / \mathrm{m}$ dan harga

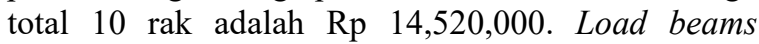
berjumlah 2 buah yang memiliki panjang satuan $8 \mathrm{~m}$ per rak dengan harga per meter $242,000 / \mathrm{m}$ dan harga total 10 rak adalah Rp 38,720,000. Siku Penopang berjumlah 4 buah yang memiliki panjang satuan 0.31 
m per rak dengan harga Rp 60,000/pcs dan harga total 10 rak adalah $\mathrm{Rp} 2,400,000$. Baut berjumlah 32 buah dengan harga per picis $450,00 /$ pcs dan harga total 10 rak adalah $\mathrm{Rp} 144,000$.

\section{REFERENSI}

[1] L. Gozali, I A. Marie, Natalia, G. M. Kustandi, E. Adisurya. Suggestion of Raw Material Warehouse Layout Improvement Using Class-Based Storage Method (case study of PT XYZ). IOP Conf. Series: Materials Science and Engineering. 2020. Doi:10.1088/1757-899X/1007/1/012024

[2] P. Baker dan M. Canessa. Production, Manufacturing and Logistics, Warehouse design: A structured approach. European Journal of Operational Research 193, 2009, 425-436 https://doi.org/10.1016/j.ejor.2007.11.045

[3] Y. Muharni, Kulsum, dan M. Khoirunnisa. Warehouse Layout Designing of Slab Using Dedicated Storage and Particle Swarm Optimization. IOP Conf. Series: Materials Science and Engineering 532, 2019. Doi: 10.1088/1757-899X/532/1/012003

[4] D. Meldra dan H. M. Purba. Relayout Tata Letak Gudang dengan menggunakan metode dedicated storage. Jurnal Rekayasa Sistem Industri, Vol.4, No.1, 2018.

http://ejournal.upbatam.ac.id/index.php/rsi/article/vie $\mathrm{w} / 813$

[5] D. F. Nurcholistyanto, N. R. Hidayati, dan F. Nugrahanti. Rancang Bangun Aplikasi Gudang Berbasis Dekstop Dengan Menggunakan Java Netbeans Studi Kasus di PT INKA (Persero). Seminar Nasional Teknologi Informasi dan Komunikasi, SENATIK 2018. http://prosiding.unipma.ac.id/index.php/SENATIK/ar ticle/view/1268

[6] A. A. Arrazani dan I. A. Primasari. Usulan Perancangan Ulang Tata Letak Fasilitas pada PT Industri Kereta Api (Persero) Menggunakan Metode ALDEP. Thesis. Yogyakarta \& Universitas Ahmad Dahlan. http://eprints.uad.ac.id/15607/

[7] F. L. Camerawati dan H. Handoyo. Perancangan Ulang Tata Letak Fasilitas Gudang Bahan Baku dengan Metode Systematic Layout Planning (SLP) di P INKA Multi Solusi. Jurnal Manajemen Industri dan Teknologi, Vol. 02, No. 03, 2021, 59 - 70. http://juminten.upnjatim.ac.id/index.php/juminten 